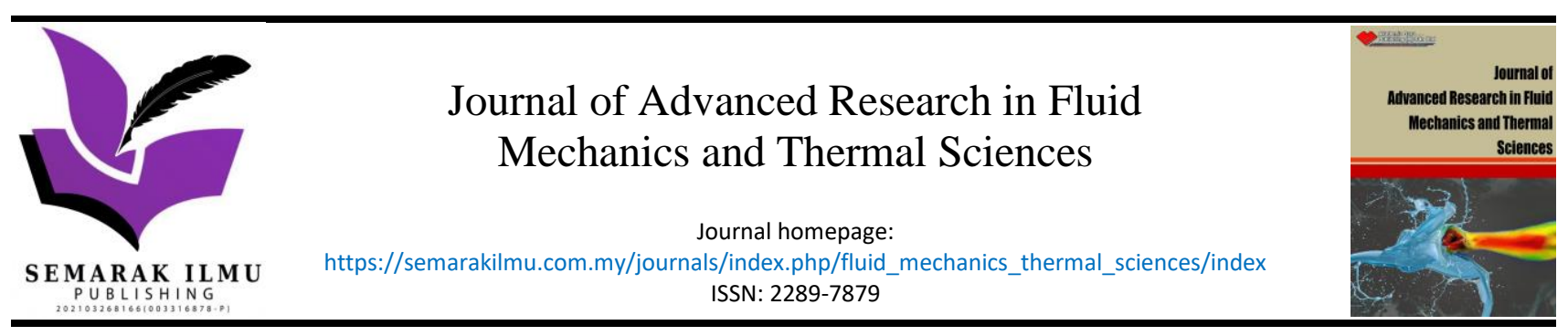

\title{
A Brief Review on Radiant Cooling Panel with Different Chilled Water Pipe Configurations
}

\author{
Mohammad Hakim Mohd. Radzai ${ }^{1}$, Chin Wai Lim ${ }^{1}{ }^{*}$, Chong Tak Yaw ${ }^{2}$, Siaw Paw Koh², Nur Amirani \\ Ahmad $^{1}$, Mohammad Shakeri ${ }^{2}$, Jagadeesh Pasupuleti ${ }^{2}$ \\ Department of Mechanical Engineering, Universiti Tenaga Nasional (The National Energy University), Jalan IKRAM-UNITEN, 43000, Kajang \\ Selangor, Malaysia \\ 2 Institute of Sustainable Energy, Universiti Tenaga Nasional (The National Energy University), Jalan IKRAM-UNITEN, 43000, Kajang Selangor, \\ Malaysia
}

\section{ARTICLE INFO}

\section{Article history:}

Received 28 July 2021

Received in revised form 9 October 2021

Accepted 15 October 2021

Available online 29 November 2021

\section{Keywords:}

Canopy-to-Canopy Flow; Heat Transfer; Pipe Design; Radiant Cooling Panel; Serpentine Flow

\section{ABSTRACT}

Radiant cooling systems are commonly applied in commercial applications because of their energy-saving potential. This potential can be further enhanced by evaluating the cooling performance of the radiant cooling panel in terms of flow configurations. Although studies have been conducted on the flow configurations of the radiant cooling panel, the most suitable flow configurations have yet to be determined. The conventional serpentine flow configuration does not bring out the best cooling performance of the radiant cooling panel, therefore different flow configurations are still needed to be explored. This study conducted a quick literature review on the different radiant cooling systems as well as radiant cooling panel with different chilled water pipe configurations. The objective of this review is to provide a brief comparison of the performance of radiant cooling panel with different chilled water pipe configurations and to suggest further studies for the system development. The cooling characteristics and heat transfer of the panel are investigated by using numerical study. A comparison between the designs of flow configurations is presented. In all of the cases, the plate area and flow volume are fixed. Based on the findings obtained, applying a different chilled water pipe configuration on the radiant cooling panel will affect the flow uniformity and also the temperature distribution uniformity. An optimized flow configurations for the radiant cooling panel is important for enhancing the overall efficiency of the system.

\section{Introduction}

Radiant cooling $(\mathrm{RC})$ systems are one of the alternatives in achieving thermal comfort other than the traditional air-conditioning systems. RC systems are gaining popularity in recent years based on their energy-saving capability and the potential in achieving higher thermal comfort. RC systems also supply good indoor air quality (IAQ) compared to conventional all-air systems [1]

\footnotetext{
* Corresponding author.

E-mail address: Ichinwai@uniten.edu.my
}

https://doi.org/10.37934/arfmts.89.2.114 
The use of an RC system can cut down sensible loads thus reducing the ventilation air needs to a minimum [2]. The heat transfer for the same amount of heat is more efficient by using an RC system compared to the all-air cooling system as water has a higher thermal capacity than air [2]. Therefore, the building's energy-saving can further increase by cutting down the costs of energy used by traditional all-air cooling systems [2].

Imanari et al., [3] has claimed that radiant cooling can provide more comfortable thermal conditions than conventional all-air systems. To learn more about the thermal comfort of a radiant cooling system, Tian et al., [4] conducted a field study of occupant thermal comfort and thermal environments with radiant cooling slabs system in the Information and Communication Technology (ICT) building located at University of Calgary. The study conducted was a combination of field measurements and questionnaires based on American Society of Heating, Refrigerating and AirConditioning Engineers (ASHRAE) research project (RP)-921 project protocol [4].

Based on Tian et al., [4], the average indoor air temperature was $22.3^{\circ} \mathrm{C}$ in both summer and winter with a temperature range of $20.7-24^{\circ} \mathrm{C}$. The mean air velocity was $0.06 \mathrm{~m} / \mathrm{s}$ with $36 \%$ average relative humidity in summer and $11 \%$ in winter. Based on ASHRAE 55-2004 [5], the allowable vertical air temperature difference between head and ankles is lower than $3^{\circ} \mathrm{C}$ and the allowable range of floor temperature is $19-29^{\circ} \mathrm{C}$. The study conducted by Tian et al., [4] proves that the radiant cooling system follows the thermal comfort standard with the average vertical air temperature difference between head and ankles is $0.5^{\circ} \mathrm{C}$. Moreover, the average floor temperature obtained was $21^{\circ} \mathrm{C}$ for both of the seasons which falls in the $19-29^{\circ} \mathrm{C}$ range as mentioned in ASHRAE 55-2004 [5].

Tian et al., [4] has claimed that the radiant cooling system provides a lower actual overall dissatisfaction than the total predicted dissatisfaction from general and local discomfort. This is due to the local discomfort produced from draft and vertical air temperature difference is effectively reduced by the radiant cooling systems compared to the mixed-air systems [4].

RC systems are mostly applied in commercial applications and are widely installed in airports [69], offices [10-13], schools [6, 14-16], museums [8, 17-20], and etc. [21-27]. The places of installation are in large public areas that need extensive cooling $[28,29]$. However, an RC system can also be installed in a residential area, but it needs to be controlled carefully [23, 30-32].

Most RC home applications use ceiling radiant cooling panels (CRCP) in which chilled water is circulated in the water pipe installed on aluminium panels suspended from the ceilings $[1,31,33]$. CRCP cools down the surface temperature of the ceiling thus absorbing heat radiated by everything in the room including the occupants [33]. Sensible heat is removed from the occupant body mainly by thermal radiation and heat exchange only occurs between people and object without the need of cooled air. Therefore, thermal comfort of the occupant can be achieved with warmer interior air temperatures. The general idea of RC is shown in Figure 1 [34]. 


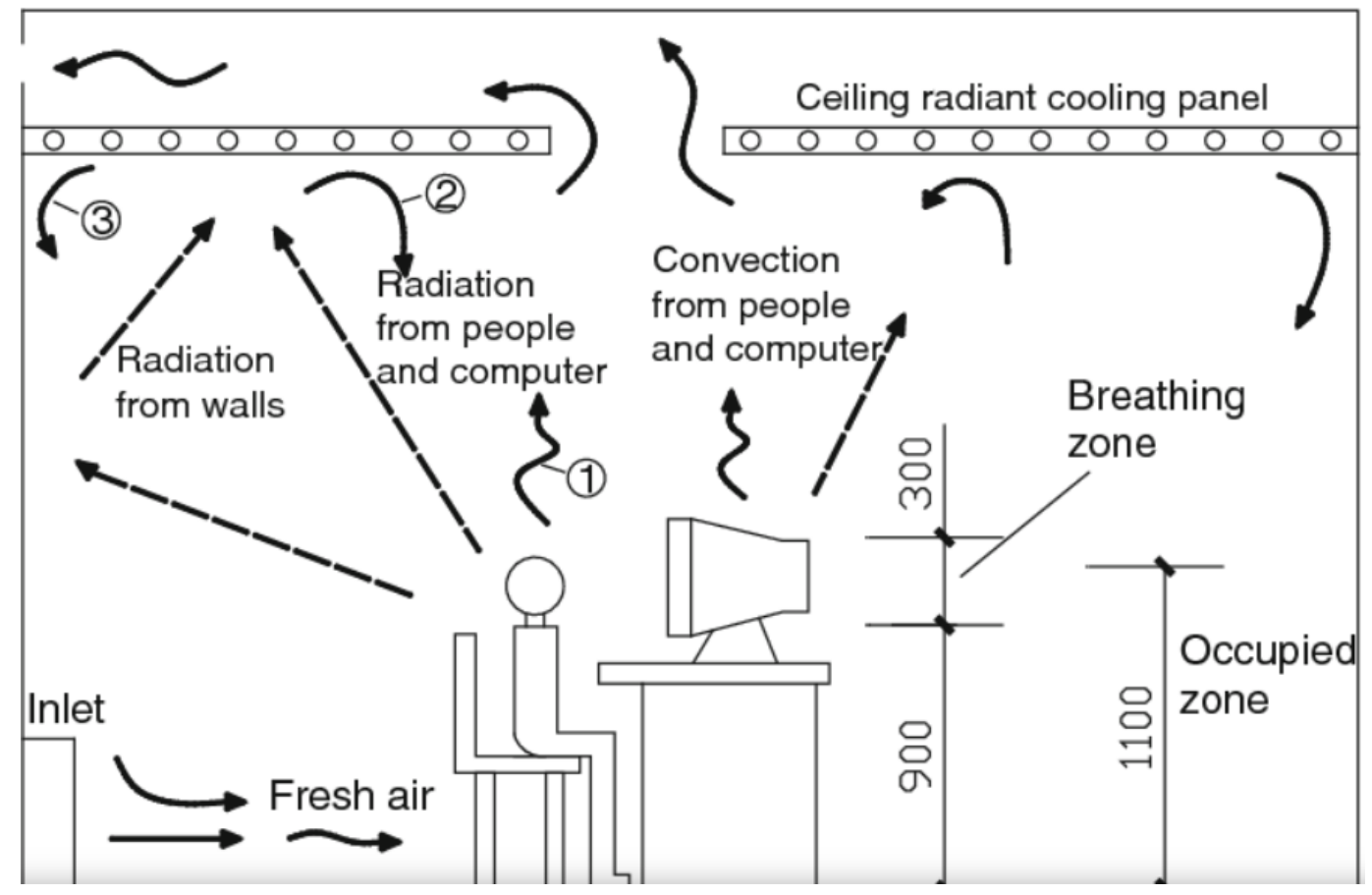

Fig. 1. General Idea for Radiant Cooling System [34]

For the RC system to be effective, the minimum exterior temperature of the panels must be kept slightly higher than the dew point temperature within the house $[33,35,36]$. If the surface temperature of the panel is lower than the dew point temperature, condensation may occur thus decreasing its effectiveness [36]. On the other hand, it is recommended to use a dedicated outdoor air system (DOAS) together with the radiant cooling system $[1,37,38]$. As long as radiant panel loop temperature control and DOAS are operating correctly, condensation can be avoided [1, 37-39].

This study conducted a quick literature review on the different radiant cooling system as well as radiant cooling panel with different chilled water pipe configurations. The objectives of this review are to provide a brief comparison of the performance of radiant cooling panel with different chilled water pipe configurations and to suggest further studies for the system development.

\section{Types of Radiant Panel System}

Various types of radiant cooling systems have been developed to suit better in different climates and surroundings. Their performance might differ from place to place. The radiant cooling system is divided into three groups which are the thermally active building systems, radiant cooling panel, and capillary tube system.

\subsection{Thermally Active Building Systems (TABS)}

A thermally active building system (TABS) uses water pipes that are thermally coupled to the building structure such as walls and slabs [40-42]. A schematic of TABS is shown in Figure 2. The water pipes are embedded in the concrete floor and utilize the concrete thermal mass for heating and cooling in the building's structure [42-44]. Therefore, sensible cooling in the building is mainly contributed by the chilled surface of walls, ceilings, and floors [44-46]. 


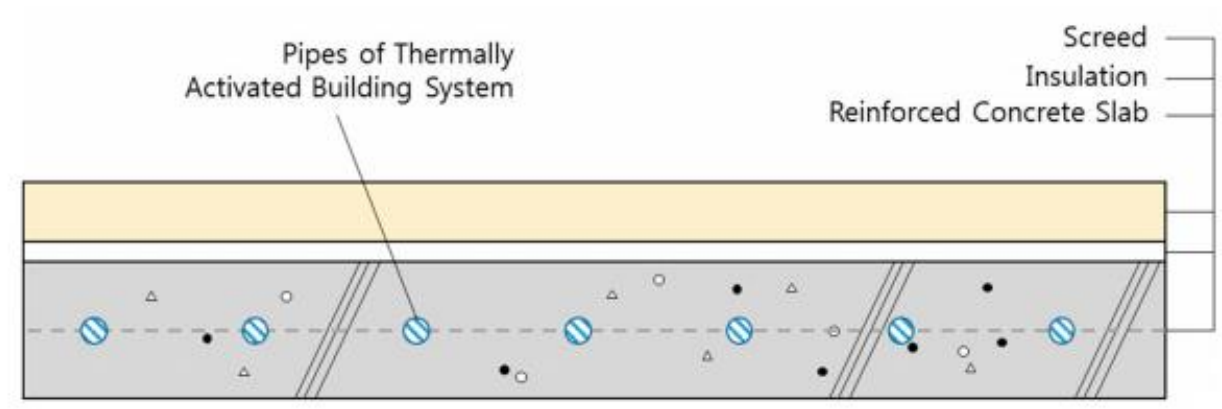

Fig. 2. Section view of thermally active building systems (TABS) [47]

TABS can provide adequate thermal comfort with low energy usage $[48,49]$. TABS are also cost effective as it is installed during the construction phase and is capable to persist for the whole life of the building structure [48-50]. Besides that, TABS can ensure healthy indoor environment by providing optimal indoor temperature through a silent system that does not circulate air, dust, and draught [48-50]. The main disadvantage of TABS is that it is not feasible to be installed in an existing building. It is only used in new construction projects that prioritize green design element [50].

\subsection{Thermally Radiant Cooling Panel (RCP)}

A radiant cooling panel (RCP) is a panel consists of integrated water pipes and the panel is mostly suspended under the ceiling [1]. RCP can be used in both retrofitted and new buildings as the panel provides flexibility for zoning and easy installation compared to the radiant system types that have to embed water pipes in the concrete layer of the building $[1,35]$. Metal ceiling RCP is widely installed and used on T-bar grids to support the suspended panel under the ceiling [51-55]. There are top insulated ceiling RCP and free-hanging ceiling RCP without topside insulation. The top insulated ceiling RCP is to prevent heat gain from the plenum space while the free-hanging ceiling RCP uses both top and bottom panel surfaces as heat transfer surfaces [51-55]. A sample of RCP is shown in Figure 3.

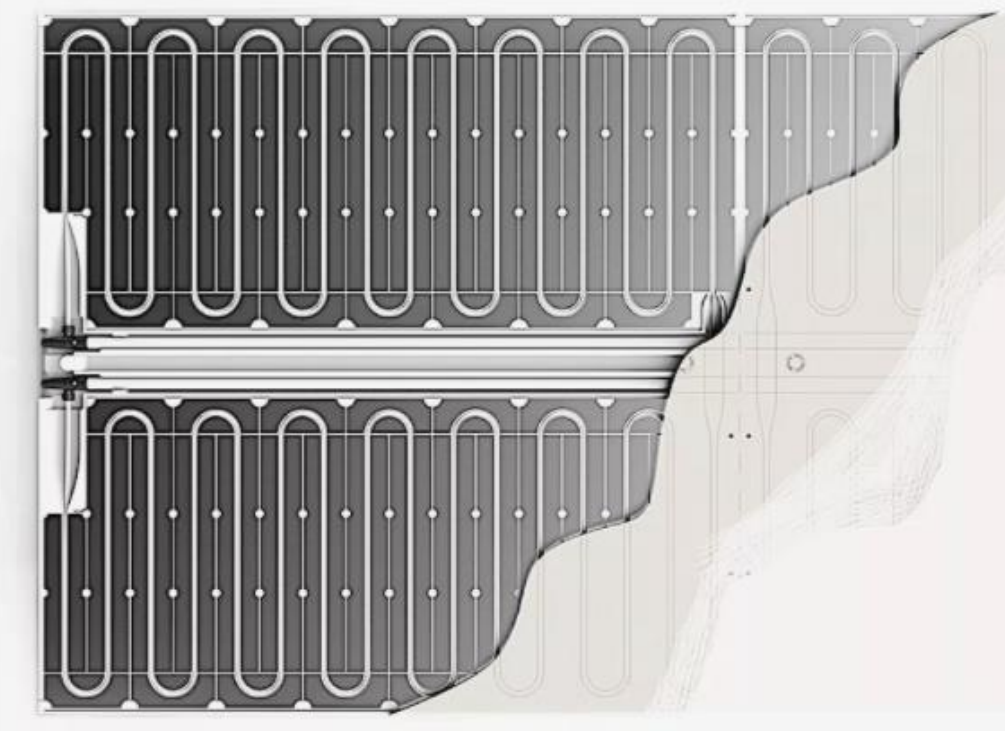

Fig. 3. Messana radiant cooling panel [56] 
RCP have the same benefit as TABS and capillary tube system (CTS) where it can provide adequate thermal comfort with low energy usage and also can provide quiet cooling solution. What makes RCP stand out among other radiant cooling systems is the ease of installation $[57,58]$. RCP have seamless integration where the installation of the system is the easiest compared to TABS and CTS [58]. However, RCP also suffer from condensation problem and can be prevented by increasing the supply water temperature to be higher than the dew point temperature of the room.

\subsection{Capillary Tube System (CTS)}

Capillary tubes are placed closely with each other on the cooling grid and are usually embedded in plaster or gypsum board $[51,59]$. A capillary tube system can also be mounted on the ceiling panels and can be made in a form of a mat [59-61]. This system can ensure uniform surface temperatures as the tubes have narrow spacing between them. Figure 4 is one of the samples of CTS.

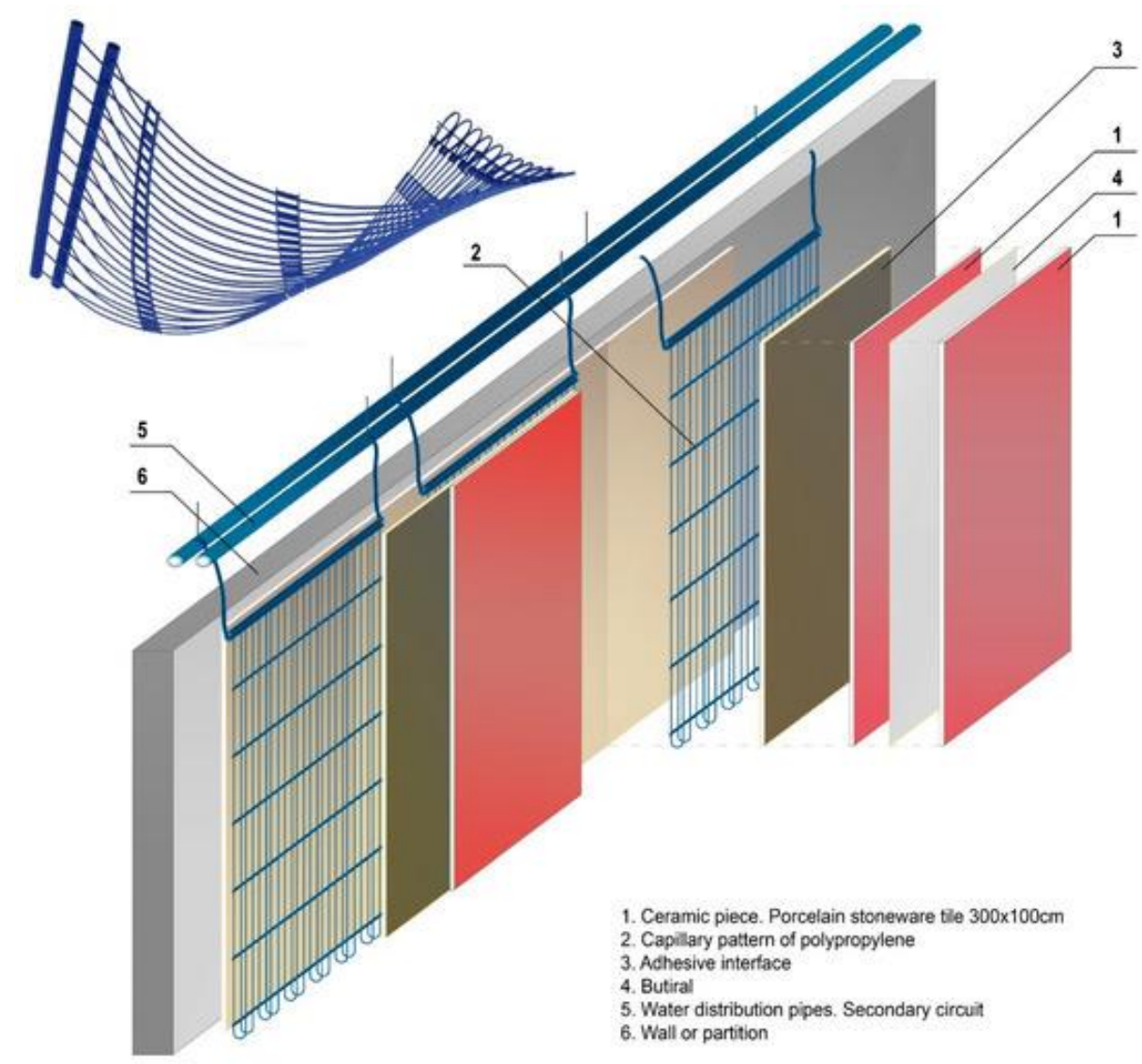

Fig. 4. Ceramic thermal conditioning panel using capillary tube system [65]

Interior surfaces with capillary tube mats have continuous temperature stability and allow for rapid dissipation of cooling loads or distribution of heat requirements, which is roughly $60 \%$ by radiation and $40 \%$ through convection [62]. The capillary tube mats have easy installation and can be installed under the surface decorative materials on walls, ceiling and floor. The energy transfer by this system produces zero noise thus thermal comfort can be achieved without any noise pollution by the system[63]. However, installations of the CTS in cold climatic zones are limited mostly by the system's heating power while the uses of the CTS in high-humidity areas are limited by the need to prevent condensation [64]. Clogging of the radiant cooling system can also be a problem when using plastic capillary tubes due to the tiny tubes that are commonly used in capillary tube mats [64]. 


\subsection{Summary of Radiant Panel System}

A summary of advantages and disadvantages for radiant panel system is shown in Table 1.

\section{Table 1}

Advantages and disadvantages of the radiant panel system.

\begin{tabular}{|c|c|c|}
\hline $\begin{array}{l}\text { Types of Radiant Panel } \\
\text { System }\end{array}$ & Advantages & Disadvantages \\
\hline $\begin{array}{l}\text { Thermally Active Building } \\
\text { Systems (TABS) }\end{array}$ & $\begin{array}{l}\text { Provide adequate thermal comfort } \\
\text { with low energy usage. } \\
\text { - Cost effective as it is installed during } \\
\text { the construction phase. } \\
\text { Ensure healthy indoor environment } \\
\text { by providing optimal indoor } \\
\text { temperature. }\end{array}$ & $\begin{array}{l}\text { - Cannot be installed in an } \\
\text { existing building. } \\
\text { Only used in new } \\
\text { construction projects that } \\
\text { prioritize green design } \\
\text { element. }\end{array}$ \\
\hline $\begin{array}{l}\text { Thermally Radiant Cooling } \\
\text { Panel } \\
\text { (RCP) }\end{array}$ & $\begin{array}{l}\text { Can be used in retrofitted and new } \\
\text { buildings as the panels provide } \\
\text { flexibility for zoning and easy } \\
\text { installation. } \\
\text { Provide adequate thermal comfort } \\
\text { with low energy usage. }\end{array}$ & $\begin{array}{l}\text { - } \quad \text { Have condensation problem. } \\
\text { - Need high supply water } \\
\text { temperature. }\end{array}$ \\
\hline $\begin{array}{l}\text { Capillary Tube System } \\
\text { (CTS) }\end{array}$ & $\begin{array}{l}\text { - } \quad \text { Ensure uniform surface } \\
\text { temperatures. } \\
\text { Interior surfaces with capillary tube } \\
\text { mats have continuous temperature } \\
\text { stability. } \\
\text { Easy installation and can be installed } \\
\text { under the surface decorative } \\
\text { materials. } \\
\text { Provide adequate thermal comfort } \\
\text { with low energy usage. }\end{array}$ & $\begin{array}{l}\text { - Have condensation problem. } \\
\text { Clogging of the radiant } \\
\text { cooling system due to the } \\
\text { closely arranged tiny tubes. }\end{array}$ \\
\hline
\end{tabular}

\section{Results Performance of RCP with Different Flow Configurations}

The flow configurations of RCP are divided into serpentine design and canopy-to-canopy design.

\subsection{Serpentine Flow Design}

A typical radiant panel has a copper pipe with a serpentine flow design set on top of an aluminum plate [66-70]. The panel is covered with an insulation layer that has a small gap filled with air [71]. In other words, a single pipe of fixed diameter is bent into an S-shaped and positioned parallel to each other to create the serpentine layout. Some sample of serpentine flow arrangement are shown in Figure 5. 


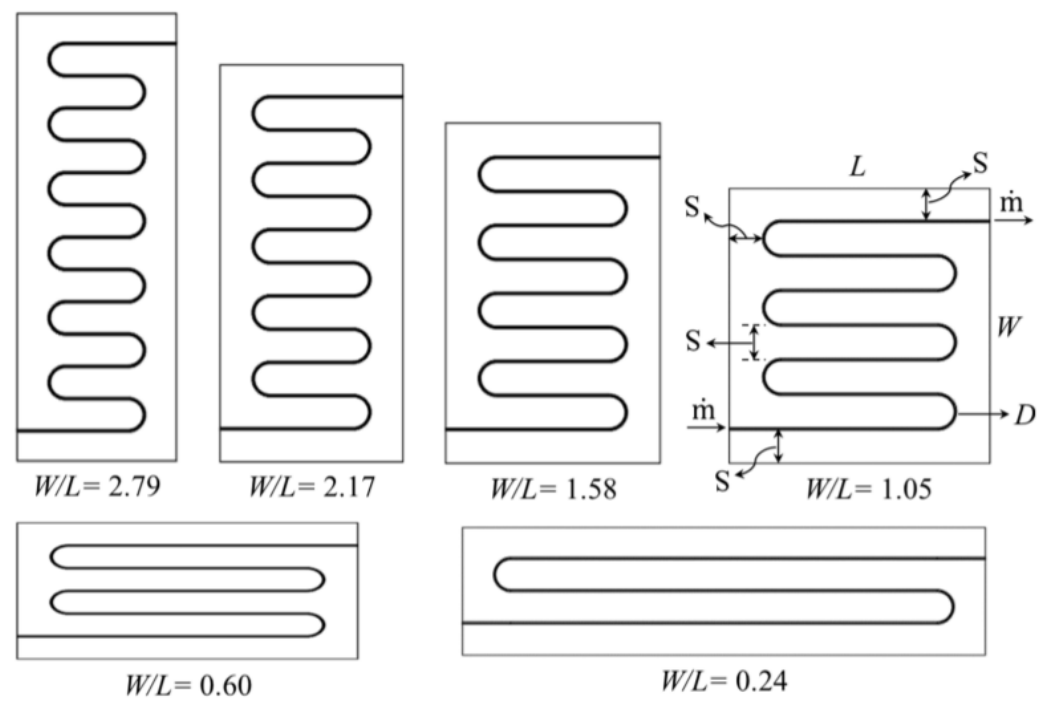

Fig. 5. Sample of serpentine flow arrangement with the different aspect ratio [66]

A simulation on the different aspect ratios of serpentine flow design was carried out by Mohamed Mosa et al., [66] to find the best flow configuration for a radiant cooling panel. Based on the simulation, the researcher found out that a serpentine flow with an aspect ratio of 0.24 has a more uniform panel temperature but it is said that the plate temperature is hotter than a higher aspect ratio panel. The cooling capacity of a higher aspect ratio panel is enhanced slightly compared to that of a panel with a lower aspect ratio. However, there is a greater pressure drop across the panel with a higher aspect ratio due to the increasing number of bends over the serpentine pipe total length. More pumping power is required on a serpentine pipe with higher aspect ratios. Mohamed Mosa et al., [66] proofed that increasing the aspect ratio of the serpentine flow design does not improve the panel's cooling capacity significantly. Therefore, exploration of different flow arrangements and configurations are required to improve the overall performance of the radiant cooling panel.

\subsection{Canopy-to-Canopy Flow Design}

A canopy-to-canopy design is taken from a tree structure design $[66,72,73]$ and is shown in Figure 6. $D_{1}$ is the main pipe diameter which is also known as the tree trunk while diameter $D_{2}$ is its branches. The canopy-to-canopy flow design has one inlet and one outlet. Cooling fluid enters the inlet and then flows into equally spaced pipes that are parallel with each other before merging back into the outlet pipe.

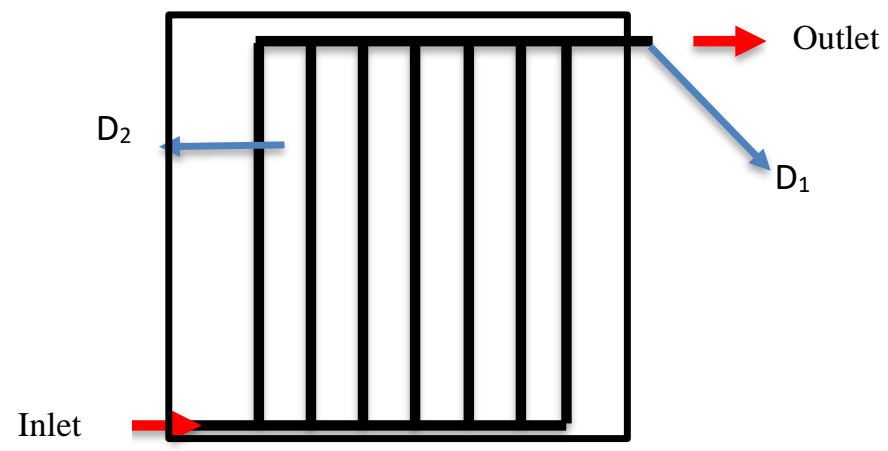

Fig. 6. General of Canopy-to-canopy flow design 
There were two simulations done by Mohamed Mosa et al., [66] through manipulating the pipe's diameter $\left(D_{1}\right.$ and $\left.D_{2}\right)$. The first simulation was conducted with a constant $D_{1}$ throughout the pipes while the second simulation was conducted by changing the $D_{1}$ and $D_{2}$, meaning that there were two different diameters in the second simulation. Based on the results of the simulations, it concluded that the panel aspect ratio does not affect the flow distribution of the single diameter canopy-tocanopy flow design significantly. However, for the two diameters canopy-to-canopy flow design, the mass flow rate distribution is smoothened in the parallel channels without taking the panel aspect ratio into account. A minimum pressure drop is achieved by the canopy-to-canopy flow design with two different diameters.

\subsection{Summary of Flow Design}

Mohamed Mosa et al., [66] claimed that the canopy-to-canopy flow design produced a better cooling capacity per pumping power compared to the serpentine flow design. The two-diameter canopy-to-canopy flow design with a 1.05 aspect ratio has a better performance than any other flow design. Based on this investigation, a two-diameter design can improve the cooling capacity of the panel with low pumping power demand. Nevertheless, there is a lot more possible designs that can be implemented in the radiant cooling panel to achieve a better panel temperature distribution and smaller pumping power.

A multi segmented mini-channel radiant ceiling cooling panel (MCRCP) is a new RCP design proposed by Lan Ding et al., [74]. The schematic diagram of the proposed MCRCP is shown in Figure 7 [74]. Lan Ding et al., [74] claims that the conventional serpentine flow design with a large panel area will limit the cooling capacity of the RCP. The advantage of MCRCP design is that it can give a significant improvement on the cooling capacity of the MCRCP by increasing the surface area of the panel which cannot be achieved by the conventional serpentine flow RCP [74]. For the same ceiling coverage ratio, increasing the surface area of MCRCP can greatly increase the maximum permissible cooling capacity [74].

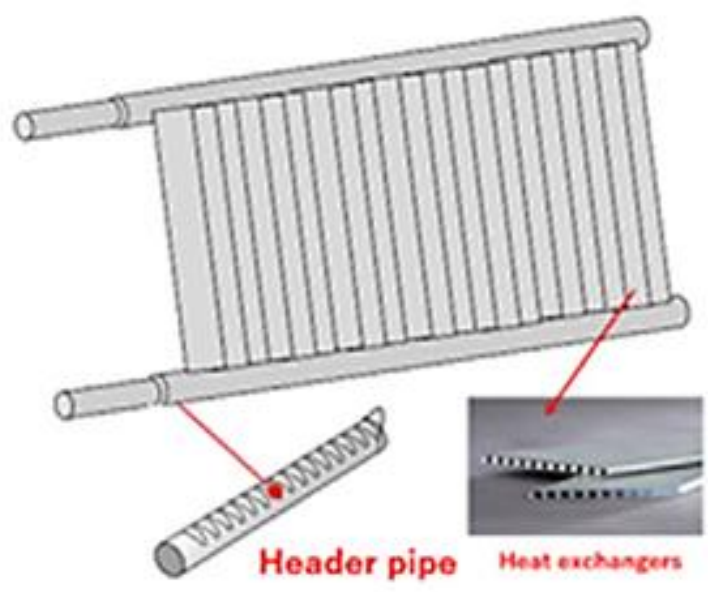

Fig. 7. Schematic diagram of MCRCP [74]

Based on the findings of Mohamed Mosa et al., [66] and Lan Ding et al., [74], the aspect ratio of the RCP can give a significant impact on the cooling performance of the RCP. Different aspect ratio is needed for different design of RCP in order to gain the maximum cooling performance from the RCP. Therefore, the aspect ratio of the RCP is an important factor that should be taken into consideration when designing new RCP flow configurations. A summary of flow design is shown in Table 2. 


\section{Table 2}

Summary of research findings on the RCP with different flow configurations

\begin{tabular}{|c|c|c|}
\hline $\begin{array}{l}\text { RCP with Different Flow } \\
\text { Configurations }\end{array}$ & Definitions & Findings \\
\hline Serpentine Flow & $\begin{array}{l}\text { A single pipe of fixed } \\
\text { diameter is bent into an S- } \\
\text { shaped and positioned } \\
\text { parallel to each other to } \\
\text { create the serpentine layout. }\end{array}$ & $\begin{array}{l}\text { A serpentine flow with } \\
\text { smaller aspect ratio has a } \\
\text { more uniform panel } \\
\text { temperature but the plate } \\
\text { temperature is hotter than a } \\
\text { higher aspect ratio panel. }\end{array}$ \\
\hline Canopy-to-Canopy Flow & $\begin{array}{l}\text { - A canopy-to-canopy design is } \\
\text { taken from a tree structure } \\
\text { design. } \\
\text { Cooling fluid enters the inlet } \\
\text { and then flows into equally } \\
\text { spaced pipes that are parallel } \\
\text { with each other before } \\
\text { merging back into the outlet } \\
\text { pipe. }\end{array}$ & $\begin{array}{l}\text { The cooling performance of a } \\
\text { canopy-to-canopy flow } \\
\text { design is not affected } \\
\text { by the panel aspect ratio. }\end{array}$ \\
\hline $\begin{array}{l}\text { Multi Segmented Mini-Channel } \\
\text { Flow }\end{array}$ & $\begin{array}{l}\text { - Have header pipe with a mini } \\
\text { channel that flows into the } \\
\text { multi segmented heat } \\
\text { exchangers. } \\
\text { - The angle between the } \\
\text { inclined segment and header } \\
\text { pipe can be manipulated. }\end{array}$ & $\begin{array}{l}\text { - The cooling capacity of the } \\
\text { MCRCP increases when the } \\
\text { aspect ratio of the panel } \\
\text { increases. } \\
\text { Further increasing the aspect } \\
\text { ratio of the panel after a peak } \\
\text { cooling performance have } \\
\text { been obtained will result in } \\
\text { decreasing cooling capacity } \\
\text { of the MCRCP. }\end{array}$ \\
\hline
\end{tabular}

\section{Results Parameters to Determine the Heating and Cooling Capacity of Radiant Panel}

Rhee et al., [6] proposed that heat transfer at each element of the radiant cooling and heating system are important criteria in determining the cooling and heating capacity of the radiant system. The heat transfer in the system depends on the heat exchange between the occupied space and the radiant surface. Besides that, it also depends on the heat conduction between the panel surface and the panel's pipe as well as the flow dynamics of water inside the pipe. Therefore, important parameters can be determined by understanding the heat exchange that occurs in the system. One of the parameters is the coefficient of convective and radiant heat exchange. Based on Rhee et al., [6], the radiant heat transfer coefficient is generally about $5.5 \mathrm{~W} /\left(\mathrm{m}^{2} \mathrm{~K}\right)$, while the convective heat transfer coefficient is between 0.3 and $6.5 \mathrm{~W} /\left(\mathrm{m}^{2} \mathrm{~K}\right)$. The coefficient of both convective and radiant heat exchange have a direct proportionality to the heating or cooling capacity of the radiant panel. On the other hand, parameters such as the surface material, piping system, pipe spacing, mass flow 
rate of water, supply water temperature and return water temperature are also important and should be taken into account when designing a radiant heating or cooling system.

\section{Conclusion}

Finally, it can be concluded that the efficiency of the radiant cooling panel can be enhanced with the proper investigation of flow configurations. From this article, the aspect ratio and flow configurations of the radiant cooling panel can give a significant impact on its performance in terms of temperature distribution and pressure drop. Pressure drop is highly related to pumping power and with lesser pressure drop, smaller pumping power can be achieved that will increase the energysaving potential of the panel. Based on the review results, conventional serpentine flow configuration does not bring out the best cooling performance of the radiant cooling panel. Instead, canopy-tocanopy flow configuration gives a better cooling performance that results in a higher cooling capacity with lesser pumping power. Based on this comparison, it is suggested that increasing the number and location of pipe inlets and outlets as well as the compactness of the pipe arrangement has the potential on improving the cooling performance.

The design of a radiant cooling panel should provide satisfactory indoor cooling performance. In order to achieve this, it is recommended that different design groups and flow configurations of the radiant cooling panel should be explored and investigated in the search for a better panel design and flow configurations.

\section{Acknowledgement}

The authors wish to thank the Ministry of Education of Malaysia (MOE) for funding this study through the Fundamental Research Grant Scheme (FRGS) grant research (FRGS/1/2018/TK03/UNITEN/02/3).

\section{References}

[1] Ning, Baisong, Youming Chen, Hui Liu, and Shunbo Zhang. "Cooling capacity improvement for a radiant ceiling panel with uniform surface temperature distribution." Building and Environment 102 (2016): 64-72. https://doi.org/10.1016/i.buildenv.2016.03.009

[2] Karmann, Caroline, Stefano Schiavon, and Fred Bauman. "Thermal comfort in buildings using radiant vs. all-air systems: A critical literature review." Building and Environment 111 (2017): $123-131$. https://doi.org/10.1016/i.buildenv.2016.10.020

[3] Imanari, Takehito, Toshiaki Omori, and Kazuaki Bogaki. "Thermal comfort and energy consumption of the radiant ceiling panel system.: Comparison with the conventional all-air system." Energy and buildings 30, no. 2 (1999): 167175. https://doi.org/10.1016/S0378-7788(98)00084-X

[4] Tian, Zhen, and James A. Love. "A field study of occupant thermal comfort and thermal environments with radiant slab cooling." Building and Environment 43, no. $10 \quad$ (2008): 1658-1670. https://doi.org/10.1016/i.buildenv.2007.10.012

[5] Standard, A. S. H. R. A. E. "Standard 55-2004, Thermal environmental conditions for human occupancy." American Society of Heating, Refrigerating and Air Conditioning Engineers, Atlanta, GA (2004).

[6] Rhee, Kyu-Nam, Bjarne W. Olesen, and Kwang Woo Kim. "Ten questions about radiant heating and cooling systems." Building and Environment 112 (2017): 367-381. https://doi.org/10.1016/i.buildenv.2016.11.030

[7] Zhao, Kang, Xiao-Hua Liu, and Yi Jiang. "On-site measured performance of a radiant floor cooling/heating system in Xi'an Xianyang International Airport." Solar Energy $108 \quad$ (2014): $274-286$. https://doi.org/10.1016/i.solener.2014.07.012

[8] Vangtook, Prapapong, and Surapong Chirarattananon. "An experimental investigation of application of radiant cooling in hot humid climate." Energy and buildings 38, no. $4 \quad$ (2006): $273-285$. https://doi.org/10.1016/j.enbuild.2005.06.022

[9] Liu, Xiaochen, Xiaohua Liu, Tao Zhang, and Lingshan Li. "An investigation of the cooling performance of airconditioning systems in seven Chinese hub airport terminals." Indoor and Built Environment 30, no. 2 (2021): 229 244. https://doi.org/10.1177/1420326X19891645 
[10] Mustakallio, Panu, Zhecho Bolashikov, Lauris Rezgals, Aleksandra Lipczynska, Arsen Melikov, and Risto Kosonen. "Thermal environment in a simulated double office room with convective and radiant cooling systems." Building and Environment 123 (2017): 88-100. https://doi.org/10.1016/i.buildenv.2017.06.029

[11] Corgnati, Stefano Paolo, Marco Perino, Giovanni Vincenzo Fracastoro, and Peter V. Nielsen. "Experimental and numerical analysis of air and radiant cooling systems in offices." Building and Environment 44, no. 4 (2009): 801806.https://doi.org/10.1016/i.buildenv.2008.05.022

[12] Mustakallio, Panu, Zhecho Bolashikov, Kalin Kostov, Arsen Melikov, and Risto Kosonen. "Thermal environment in simulated offices with convective and radiant cooling systems under cooling (summer) mode of operation." Building and Environment 100 (2016): 82-91. https://doi.org/10.1016/j.buildenv.2016.02.001

[13] Zhao, Weixin, Simo Kilpeläinen, Risto Kosonen, Juha Jokisalo, Sami Lestinen, Yuxin Wu, and Panu Mustakallio. "Human response to thermal environment and perceived air quality in an office with individually controlled convective and radiant cooling systems." Building and Environment 195 (2021): 107736. https://doi.org/10.1016/i.buildenv.2021.107736

[14] Bayoumi, Mohannad. "Method to integrate radiant cooling with hybrid ventilation to improve energy efficiency and avoid condensation in hot, humid environments." Buildings 8, no. 5 (2018): 69. https://doi.org/10.3390/buildings8050069

[15] Teitelbaum, Eric, Kian Wee Chen, Forrest Meggers, Jovan Pantelic, and Adam Rysanek. "Exploring membraneassisted radiant cooling for designing comfortable naturally ventilated spaces in the tropics." Building Research \& Information (2020): 1-13. https://doi.org/10.1080/09613218.2020.1847025

[16] Ye, Qiming, Wei Shi, Linghong Xu, and Pingfang Hu. "Application of BP neural network for pre-dehumidification time prediction of capillary ceiling radiant cooling panel air conditioning system." In IOP Conference Series: Materials Science and Engineering, vol. 782, no. 5, p. 052031. IOP Publishing, 2020. https://doi.org/10.1088/1757899X/782/5/052031

[17] Yu, Likui, Huabo Hou, Xiongfeng Wan, and Huanxin Chen. "Study of the Applications of the Radiant Cooling Pane in Museum Showcases." (2006).

[18] Echarri, V., A. Galiano, M. I. Pérez-Millán, and A. B. González-Avilés. "Conditioning systems by radiant surfaces: comparative analysis of thermal ceramic panels versus the conventional systems in a museum." WIT Trans. Eng. Sci 83 (2014): 287-301. https://doi.org/10.2495/HT140261

[19] Garry Thomson. The museum environment. Elsevier, 2013.

[20] Kramer, R. P., M. P. E. Maas, M. H. J. Martens, A. W. M. Van Schijndel, and H. L. Schellen. "Energy conservation in museums using different setpoint strategies: a case study for a state-of-the-art museum using building simulations." Applied Energy 158 (2015): 446-458. https://doi.org/10.1016/j.apenergy.2015.08.044

[21] Paliaga, Gwelen, Farhad Farahmand, Paul Raftery, and Jonathan Woolley. "TABS radiant cooling design \& control in North America: Results from expert interviews." (2017).

[22] Olesen, Bjarne. "Radiant floor cooling systems." Ashrae Journal 50, no. 9 (2008): 16-22.

[23] Zhai, Xiaoqiang, Yuwu Li, Xiwen Cheng, and Ruzhu Wang. "Experimental investigation on a solar-powered $\begin{array}{llllll}\text { absorption } \quad \text { radiant } \quad \text { cooling } & \text { system." Energy } & \text { Procedia } 70 & \text { (2015): }\end{array}$ https://doi.org/10.1016/j.egypro.2015.02.160

[24] Choi, Narae, Toshio Yamanaka, Kazunobu Sagara, Yoshihisa Momoi, and Tomoya Suzuki. "Displacement ventilation with radiant panel for hospital wards: Measurement and prediction of the temperature and contaminant

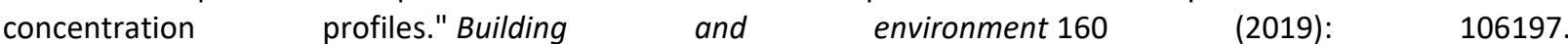
https://doi.org/10.1016/i.buildenv.2019.106197

[25] Short, C. Alan, Kevin J. Lomas, Renganathan Giridharan, and Alistair J. Fair. "Building resilience to overheating into 1960's UK hospital buildings within the constraint of the national carbon reduction target: Adaptive strategies." Building and Environment 55 (2012): 73-95. https://doi.org/10.1016/i.buildenv.2012.02.031

[26] Du, Xiaohui, Yongchao Zhang, and Zhengquan Lv. "Investigations and analysis of indoor environment quality of green and conventional shopping mall buildings based on customers' perception." Building and Environment 177 (2020): 106851.https://doi.org/10.1016/i.buildenv.2020.106851

[27] Li, Yanfei, Fuxin Niu, Defeng Qian, and P. Zheng O'Neill PhD. "Nationwide Energy Saving Analysis of Radiant Floor System for Commercial Buildings." In ASHRAE Annual Conference, Houston. 2018.

[28] Simmonds, Peter, Stefan Holst, Stephanie Reuss, and Wayne Gaw. "Using radiant cooled floors to condition large spaces and maintain comfort conditions." TRANSACTIONS-AMERICAN SOCIETY OF HEATING REFRIGERATING AND AIR CONDITIONING ENGINEERS 106, no. 1 (2000): 695-701.

[29] Zhao, Kang, Xiao-Hua Liu, and Yi Jiang. "Application of radiant floor cooling in large space buildings-A review." Renewable and Sustainable Energy Reviews $55 \quad$ (2016): 1083-1096. https://doi.org/10.1016/i.rser.2015.11.028 
[30] Waters, Rob. "Radiant Cooling: Emerging Technology Shows Promise." HPAC Magazine, March 4, 2019. https://www.hpacmag.com/features/radiant-cooling/.

[31] Su, Xiaosong, Ling Zhang, Zhongbing Liu, Yongqiang Luo, Jinbu Lian, and Yongwei Luo. "A computational model of an improved cooling radiant ceiling panel system for optimization and design." Building and Environment 163 (2019): 106312. https://doi.org/10.1016/j.buildenv.2019.106312

[32] Zarrella, Angelo, Michele De Carli, and Clara Peretti. "Radiant floor cooling coupled with dehumidification systems in residential buildings: A simulation-based analysis." Energy conversion and management 85 (2014): $254-263$. https://doi.org/10.1016/i.enconman.2014.05.097

[33] Su, Lin, Nianping Li, Xuhan Zhang, Yeyao Sun, and Jiawei Qian. "Heat transfer and cooling characteristics of concrete ceiling radiant cooling panel." Applied Thermal Engineering $84 \quad$ (2015): 170-179. https://doi.org/10.1016/i.applthermaleng.2015.03.045

[34] Du, Jing, and Nianping Li. "Study on indoor air quality of ceiling radiant cooling panel system integrated with displacement ventilation." In Proceedings of the 8th International Symposium on Heating, Ventilation and Air Conditioning, pp. 497-505. Springer, Berlin, Heidelberg, 2014. https://doi.org/10.1007/978-3-642-39584-0 56

[35] Morse, R. N. "Radiant cooling." Architectural Science Review 6, no. 2 (1963): 50-53. https://doi.org/10.1080/00038628.1963.9696068

[36] Vangtook, Prapapong, and Surapong Chirarattananon. "Application of radiant cooling as a passive cooling option in hot humid climate." Building and Environment 42, no. 2 (2007): 543-556. https://doi.org/10.1016/j.buildenv.2005.09.014

[37] Jeong, Jae-Weon, Stanley A. Mumma, and William P. Bahnfleth. "Energy conservation benefits of a dedicated outdoor air system with parallel sensible cooling by ceiling radiant panels." ASHRAE Transactions 109 (2003): 627.

[38] Lim, Hansol, and Jae-Weon Jeong. "Energy saving potential of thermoelectric radiant cooling panels with a dedicated outdoor air system." Energy and buildings 169 (2018): 353-365. https://doi.org/10.1016/i.enbuild.2018.03.062

[39] Ning, Baisong, Youming Chen, and Hongyuan Jia. "Cooling load dynamics and simplified calculation method for radiant ceiling panel and dedicated outdoor air system." Energy and Buildings 207 (2020): 109631. https://doi.org/10.1016/i.enbuild.2019.109631

[40] Lydon, Gearóid P., Stefan Caranovic, Illias Hischier, and Arno Schlueter. "Coupled simulation of thermally active building systems to support a digital twin." Energy and Buildings 202 (2019): 109298. https://doi.org/10.1016/i.enbuild.2019.07.015

[41] Domínguez, L. Marcos, Ongun B. Kazanci, Nils Rage, and Bjarne W. Olesen. "Experimental and numerical study of the effects of acoustic sound absorbers on the cooling performance of Thermally Active Building Systems." Building and Environment 116 (2017): 108-120. https://doi.org/10.1016/i.buildenv.2017.02.009

[42] Moe, Kiel. Thermally active surfaces in architecture. Princeton Architectural Press, 2010.

[43] Saelens, Dirk, Wout Parys, and Ruben Baetens. "Energy and comfort performance of thermally activated building systems including occupant behavior." Building and environment 46, no. 4 (2011): 835-848. https://doi.org/10.1016/j.buildenv.2010.10.012

[44] Lehmann, Beat, Viktor Dorer, Markus Gwerder, F. Renggli, and Jürg Tödtli. "Thermally activated building systems (TABS): Energy efficiency as a function of control strategy, hydronic circuit topology and (cold) generation system." Applied Energy 88, no. 1 (2011): 180-191. https://doi.org/10.1016/j.apenergy.2010.08.010

[45] Rijksen, D. O., C. J. Wisse, and A. W. M. Van Schijndel. "Reducing peak requirements for cooling by using thermally activated building systems." Energy and buildings 42, no. $3 \quad$ (2010): $298-304$. https://doi.org/10.1016/i.enbuild.2009.09.007

[46] Romaní, Joaquim, Alvaro de Gracia, and Luisa F. Cabeza. "Simulation and control of thermally activated building systems (TABS)." Energy and Buildings 127 (2016): 22-42. https://doi.org/10.1016/i.enbuild.2016.05.057

[47] Chung, Woong June, Sang Hoon Park, Myoung Souk Yeo, and Kwang Woo Kim. "Control of thermally activated building system considering zone load characteristics." Sustainability 9, no. $4 \quad$ (2017): 586. https://doi.org/10.3390/su9040586

[48] Henze, Gregor P., Clemens Felsmann, Doreen E. Kalz, and Sebastian Herkel. "Primary energy and comfort performance of ventilation assisted thermo-active building systems in continental climates." Energy and Buildings 40, no. 2 (2008): 99-111. https://doi.org/10.1016/i.enbuild.2007.01.014

[49] Rey Martínez, Francisco Javier, Manuel Andrés Chicote, Antonio Villanueva Peñalver, Ana Tejero Gónzalez, and Eloy Velasco Gómez. "Indoor air quality and thermal comfort evaluation in a Spanish modern low-energy office with thermally activated building systems." Science and Technology for the Built Environment 21, no. 8 (2015): 10911099. https://doi.org/10.1080/23744731.2015.1056655 
[50] Schmelas, Martin, Thomas Feldmann, and Elmar Bollin. "Savings through the use of adaptive predictive control of thermo-active building systems (TABS): A case study." Applied Energy 199 (2017): $294-309$. https://doi.org/10.1016/i.apenergy.2017.05.032

[51] Mohamed, E. T. "Design of a Radiant Panel Cooling System for Summer air conditioning." PhD diss., Ph. D. Thesis, Faculty of Engineering, University of Khartoum, Sudan, 2008.

[52] Jeong, Jae-Weon, and Stanley A. Mumma. "Practical cooling capacity estimation model for a suspended metal ceiling radiant cooling panel." building and environment 42, no. 9 (2007): 3176-3185. https://doi.org/10.1016/j.buildenv.2006.08.006

[53] Jeong, Jae-Weon, and Stanley A. Mumma. "Simplified cooling capacity estimation model for top insulated metal ceiling radiant cooling panels." Applied Thermal Engineering 24, no. 14-15 (2004): 2055-2072. https://doi.org/10.1016/i.applthermaleng.2004.01.017

[54] Yu, Guoqing, Le Xiong, Chengjun Du, and Hengtao Chen. "Simplified model and performance analysis for top insulated metal ceiling radiant cooling panels with serpentine tube arrangement." Case Studies in Thermal Engineering 11 (2018): 35-42. https://doi.org/10.1016/i.csite.2017.12.006

[55] Zhang, Lun, Xiao-Hua Liu, and Yi Jiang. "Experimental evaluation of a suspended metal ceiling radiant panel with inclined fins." Energy and Buildings 62 (2013): 522-529. https://doi.org/10.1016/i.enbuild.2013.03.044

[56] Alter, Lloyd. "Looking up to Radiant Ceilings for Heating and Cooling." Treehugger. Treehugger, May 31, 2020. https://www.treehugger.com/looking-radiant-ceilings-heating-and-cooling-4858288.

[57] Springer, David. "Radiant Ceiling Panels: An Analysis of Load Shifting, Energy Use, and Comfort in a Laboratory House Setting." ASHRAE Transactions 125 (2019): 231-238.

[58] Krajčík, Michal, and Ondřej Šikula. "The possibilities and limitations of using radiant wall cooling in new and retrofitted existing buildings." Applied Thermal Engineering $164 \quad$ (2020): 114490. https://doi.org/10.1016/i.applthermaleng.2019.114490

[59] Xie, Dong, Yun Wang, Hanqing Wang, Shunquan Mo, and Maili Liao. "Numerical analysis of temperature nonuniformity and cooling capacity for capillary ceiling radiant cooling panel." Renewable Energy 87 (2016): 11541161. https://doi.org/10.1016/i.renene.2015.08.029

[60] Cho, Jinkyun, Beungyong Park, and Taesub Lim. "Experimental and numerical study on the application of lowtemperature radiant floor heating system with capillary tube: Thermal performance analysis." Applied Thermal Engineering 163 (2019): 114360. https://doi.org/10.1016/i.applthermaleng.2019.114360

[61] FU, Yun-zhun, Ying-ling CAI, Jing LI, and Ye-yu WANG. "Technical and Economic Analysis of Heat Source Schemes of Radiant Heating System of Capillary Tube [J]." Fluid Machinery 1 (2010).

[62] Kabir, Sulaiman Muhammad, and Dr Halil Zafer Alibaba. "The Analysis of Capillary Tube System for Office Buildings in Africa. (a Case Study of Nigerian and Namibian Climate)." 1Library. Accessed December 5, 2021. https://1library.net/document/zg8go68y-analysis-capillary-office-buildings-africa-nigerian-namibianclimate.html.

[63] Kabir, Sulaiman Muhammad, and Dr Halil Zafer Alibaba. "The Analysis Of Capillary Tube System For Office Buildings In Africa. (A Case Study Of Nigerian And Namibian Climate)." International Journal of Scientific and Technology Resarch 6, no. 1 (2017): 38-42.

[64] Mikeska, Tomas, and Svend Svendsen. "Dynamic behavior of radiant cooling system based on capillary tubes in walls made of high performance concrete." Energy and Buildings 108 (2015): 92-100. https://doi.org/10.1016/i.enbuild.2015.08.050

[65] Echarri-Iribarren, Víctor, Carlos Rizo-Maestre, and Fernando Echarri-Iribarren. "Healthy climate and energy savings: using thermal ceramic panels and solar thermal panels in mediterranean housing blocks." Energies 11 , no. 10 (2018): 2707. https://doi.org/10.3390/en11102707

[66] Mosa, Mohamed, Matthieu Labat, and Sylvie Lorente. "Role of flow architectures on the design of radiant cooling panels, a constructal approach." Applied Thermal Engineering $150 \quad$ (2019): 13451352.https://doi.org/10.1016/j.applthermaleng.2018.12.107

[67] Tye-Gingras, Maxime, and Louis Gosselin. "Investigation on heat transfer modeling assumptions for radiant panels with serpentine layout." Energy and Buildings 43, no. 7 (2011): 1598-1608. https://doi.org/10.1016/j.enbuild.2011.03.004

[68] Conroy, Christopher L., and Stanley A. Mumma. "Ceiling radiant cooling panels as a viable distributed parallel sensible cooling technology integrated with dedicated outdoor air systems/discussion." Ashrae Transactions 107 (2001): 578.

[69] Grinham, Jonathan, Salmaan Craig, Donald E. Ingber, and Martin Bechthold. "Origami microfluidics for radiant cooling with small temperature differences in buildings." Applied Energy 277 (2020): 115610. https://doi.org/10.1016/i.apenergy.2020.115610 
[70] Sachit, Fadhil Abdulameer, Mohd Afzanizam Mohd Rosli, Noreffendy Tamaldin, Suhaimi Misha, and Amira Lateef Abdullah. "Modelling, validation and analyzing performance of serpentine-direct PV/T solar collector design." CFD Letters 11, no. 2 (2019): 50-65.

[71] Mumma, Stanley A. "Condensation issues with radiant cooling panels." ASHRAE IAQ Applications (2001): 16-18.

[72] Mosa, Mohamed, Matthieu Labat, and Sylvie Lorente. "Constructal design of flow channels for radiant cooling panels." International Journal of Thermal Sciences $145 \quad$ (2019): 106052. https://doi.org/10.1016/i.ijthermalsci.2019.106052

[73] Da Silveira, Thiago, Vinícius Torres Pinto, João Pedro Sarasol Neufeld, Ana Pavlovic, Luiz Alberto Oliveira Rocha, Elizaldo Domingues Dos Santos, and Liércio André Isoldi. "Applicability Evidence of Constructal Design in Structural Engineering: Case Study of Biaxial Elasto-Plastic Buckling of Square Steel Plates with Elliptical Cutout." Journal of Applied and Computational Mechanics (2021).

[74] Ding, Lan, Takao Katsura, Ali Radwan, and Katsunori Nagano. "Thermal performance analyses of a new multisegmented minichannel-based radiant ceiling cooling panel." Energy Reports 6 (2020): 1409-1415. https://doi.org/10.1016/i.egyr.2020.11.008 